\title{
EL PROCEDIMIENTO DE RESOLUCIÓN DE CONTROVERSIAS EN EL DECRETO MOP N 900 EN RELACIÓN AL DEBIDO PROCESO
}

\author{
DISPUTE SOLVING PROCEDURE IN DECREE MOP N 900 IN RELATION TO DUE \\ PROCESS.
}

Alejandro Preuss Lazo

\begin{abstract}
RESUMEN:
Los preceptos legales establecidos en el Decreto MOP N 900, que regulan la resolución de conflictos derivados del contrato de concesión, mediante una Comisión Arbitral, establecen prerrogativas que vulneran nuestro ordenamiento jurídico. En vista de esto, y mediante un análisis exhaustivo, se concluye que dicha normativa vulnera el principio Constitucional del debido proceso, al establecer un procedimiento que no respeta las garantías mínimas que aseguran un resultado justo y equitativo del conflicto.
\end{abstract}

Palabras clave:Debido proceso, Decreto MOP N 900, contrato de concesión, Comisión Arbitral.

ABSTRACT:

The legal rules established in Decree MOP* N 900, which govern the conflicts settlement derived from the contract of concessions of public works through an arbitration committee, set up prerogatives which violate our legal system. Because of that and after a thorough analysis, it is concluded that the aforementioned regulations break the constitutional principle of the due process of law when establishing a procedure which does not respect the minimum guarantees which assure a just and fair outcome of the conflict.

*MOP: Ministry of Public Works

Escuchar

Leer fonéticamente

Diccionario - Ver diccionario detallado

Key words:Due process, MOP Decree № 900, concession contract, arbitration commission.

\footnotetext{
Abogado. Académico Facultad de Ciencias Jurídicas, Universidad Católica de Temuco, Asesor Jurídico Universidad Católica de Temuco.Temuco, Chile. E.-mail: apreuss@uct.cl
}

doi: 10.7770/RCHDYCP-V3N1-ART350 
El artículo $36^{\circ}$ bis del decreto MOP $N^{\circ} 900$ dispone que las controversias o reclamaciones que se produzcan con motivo de la interpretación o aplicación del contrato de concesión o a que dé lugar su ejecución podrán ser llevadas por las partes al conocimiento de la Corte de Apelaciones de Santiago o de una "Comisión Arbitral". Sin embargo, para recurrir ante este último organismo es requisito esencial que se haya autorizado la puesta en servicio definitiva de la obra, con excepción de la declaración de incumplimiento grave del contrato de concesión².

Por su parte, y en lo referente a los aspectos técnicos y económicos de la controversia, estos podrán ser llevados al conocimiento de los organismos antes mencionados, solo cuando hayan sido sometidos previamente al conocimiento y recomendación del Panel Técnico, el cual es un órgano carente de jurisdicción, ante el cual se someten las discrepancias de carácter técnico o económico que se produzcan entre las partes durante la ejecución del contrato de concesión. Frente a esto, deberá emitir una recomendación técnica fundada, de conformidad al procedimiento público establecido en el reglamento, dentro del plazo de treinta días, desde la presentación de la discrepancia. Esta recomendación no tendrá el carácter de vinculante para las partes (Artículo $36^{\circ}$ Decreto MOP N 900).

Con respecto a la Comisión Arbitral, esta tendrá facultades de árbitro arbitrador ${ }^{3}$ en cuanto al procedimiento y apreciará la prueba conforme a las reglas de la sana crítica, admitiendo además de los medios de prueba indicados en el artículo 341 del Código de Procedimiento Civil, cualquier otro medio, indicio o antecedente que, en concepto de la Comisión, sea apto para establecer los hechos sustanciales, pertinentes y controvertidos.

En relación a su conformación, estará integrada por tres miembros, de los cuales al menos dos serán abogados. Para su elección, se hará de común acuerdo entre las partes y se elegirán de entre una nómina de expertos confeccionada por la Corte Suprema y el Tribunal de la Libre Competencia ${ }^{4}$.

La Comisión podrá, además, suspender los efectos del acto administrativo reclamado -a petición del concesionario y con audiencia del Ministerio de Obras Públicas- cuando existieren motivos graves y calificados acreditados mediante comprobantes que constituyan a lo menos presunción grave del hecho reclamado. No

2 El procedimiento de la declaración de incumplimiento grave del contrato de concesión se encuentra establecido en el artículo 28 del decreto MOP № 900.

3 En relación al procedimiento, éstos no están obligados a guardar otras reglas que la que las partes hayan expresado en el acto constitutivo del compromiso (artículo 636 Código de Procedimiento Civil).

4 Esta nómina la integran abogados y otros profesionales a través de un concurso público (art. 36 bis, inc. $2^{\circ}$ Decreto MOP N 900 ). 
obstante, la paralización de la construcción de la obra o de la prestación del servicio no podrá ser por un plazo superior a sesenta días.

En cuanto a la sentencia definitiva emitida por la Comisión, deberá ser dictada con arreglo a derecho, la que será fundada, debiendo contener las consideraciones de hecho, de derecho, técnicas y económicas sobre cuya base se haya pronunciado, no existiendo recurso alguno sobre esta resolución ${ }^{5}$.

Señalado el procedimiento de resolución de conflictos en los contratos de concesión, cuyas características principales son: las facultades de árbitro arbitrador que posee la Comisión Arbitral en cuanto al procedimiento, la imposibilidad de interposición de recursos en contra de la resolución dictada por la Comisión y la atribución de la Comisión para suspender los efectos del acto administrativo a petición del concesionario; proceder a su análisis a la luz del principio constitucional del debido proceso, para verificar si este garantiza o tutela las garantías mínimas que resguardan un procedimiento justo y racional.

\section{Falta de garantías del debido proceso en el procedimiento de resolución de controversias establecido en el decreto MOP N 900}

Del examen de las normas de procedimiento, se puede establecer que este carece del reconocimiento real y expreso de los principios básicos del debido proceso, ante lo cual no existe una tutela efectiva para los particulares, que se refleja en los siguientes argumentos:

\section{A.- Imposibilidad de interposición de recursos en contra de la resolución dictada por la Comisión Arbitral}

El artículo 36 bis no contempla la posibilidad de interponer recurso alguno. Tampoco dispone una remisión a las reglas generales que contempla el Código de Procedimiento Civil, por lo que no sería factible aplicar subsidiariamente aquellas normas de una manera expresa o categórica

El hecho que la sentencia dictada por la Comisión Arbitral no sea susceptible de recurso alguno, claramente vulnera el principio del debido proceso. Frente a esta situación, la propia Corte Suprema, a propósito del proyecto de ley que introdujo

5 Artículo $36^{\circ}$ bis Decreto MOP N 900. 
modificaciones al cuerpo normativo en comento, a través del Boletín № 5172-09 de fecha 18 de mayo de 2.009, declaró que "esta situación contrasta abiertamente con el principio de la doble instancia que debe existir en todo debido proceso y además contraría el principio de la revisión de las sentencias definitivas en los Juicios de Hacienda, lo cual se manifiesta en la consagración del trámite de la consulta para esta clase de juicios en el artículo 751 del Código de Procedimiento Civil.

Es ineludible, a juicio de esta Corte, establecer un procedimiento que contemple a lo menos la existencia del recurso de casación para efectos de impugnar la sentencia que se dicte desatendiendo el derecho. De no consagrarse el derecho a un recurso que permita impugnar la sentencia nos encontraríamos con que todos los principios que resguardan la existencia de un debido proceso carecerían del instrumento necesario para velar por su efectivo resguardo y existencia".

No debemos olvidar que, si bien la Comisión no es un tribunal, esta responde a la normas de los árbitros mixtos, es decir, su fallo debe dictarse conforme a derecho, y con la obligación de fundar su sentencia. La segunda instancia, en este sentido, es de suma importancia y absolutamente trascendental para resguardar las garantías del debido proceso.

La finalidad de la doble instancia judicial y la posibilidad de revisión del acto administrativo, es lograr que los sentenciadores se abstengan de adoptar decisiones sobre la base de un conocimiento apenas superficial de una problemática ${ }^{6}$. Históricamente, se ha estimado como conveniente que lo resuelto por un tribunal sea susceptible de ser revisado por un superior jerárquico ${ }^{7}$. En virtud de ello, es que se han regulado los efectos de la concesión del instrumento a través del cual se materializa este derecho, cual es, el recurso de apelación.

En efecto, siendo el recurso de apelación el medio de impugnación más relevante que contempla nuestro ordenamiento jurídico para impugnar las resoluciones judiciales, cuyo origen se remonta a la appelatio del Derecho Romano, puesto que bien entrado el período del Imperio, en tiempos de Augusto, ya tenía la institución los caracteres que presenta en el derecho moderno: "Llevar una cuestión decidida en primer grado ante un juez de segundo grado que vuelva a tratar el mérito de la causa y cierra su juicio con una nueva sentencia, única que tiene ya valor, al destruir la primera», como lo expone el eminente romanista Vittorio Scialogia ${ }^{8}$.

6 Thesing, Josef, Estado de Derecho y Democracia, CIEDLA, Buenos Aires, Argentina, 2a edición,1999, p. 126.

7 Scialogia, Vittorio, Procedimiento Civil Romano, Buenos Aires, 1954, pp. 362- 364.

8 Ibídem.

210 Revista Chilena de Derecho y Ciencia Política - ISSN Impreso: 0718-9389 / ISSN on line: 0719-2150 
Cabe destacar que nos encontramos ante lo que Damaska denomina un Estado Jerárquico ${ }^{9}$, en el cual se exige la profesionalización de los funcionarios permanentes -jueces- y en donde la segunda instancia es esencial y además el elemento trascendental para garantizar el Estado de Derecho.

Los motivos detrás de esta decisión legislativa pueden ser encontrados en una de las pocas sentencias que se refiere al tema, que en su considerando sexto señala -reproduciendo uno de los fundamentos de la sentencia recurrida- que "... la ley de concesiones quiso dar garantía a los inversionistas de que en caso de conflicto con el propio Estado contratante, éste no impondría su legislación positiva ni sus tribunales ordinarios de justicia. La Comisión Arbitral, en consecuencia, no está necesariamente sometida a los preceptos del derecho positivo, criterios jurídicos, ni jurisprudencia de los tribunales chilenos, salvo la Ley de Concesiones y las normas vinculantes que dieron origen al contrato de concesión respectivo" [el subrayado es mío] ${ }^{10}$.

Claramente el fundamento de la sentencia es erróneo. Primero, si bien existe una relación asimétrica entre el Estado y el ciudadano, en este caso no la hay, puesto que cuando el Estado contrata lo hace como un particular -sin soberanía- mediante sus órganos administrativos. En este orden de ideas, por tanto, el Estado bajo ningún punto de vista sería superior al concesionario, sino su igual, es por ello que el contrato de concesión durante su vigencia se rige por las normas privadas y no por las públicas como sería el caso.

Por otro lado, es parte de la esencia del Estado chileno la separación de poderes. Quien contrata con los particulares es el Estado, a través del Poder Ejecutivo, pero quien resuelve las controversias es el Poder Judicial. No existe posibilidad alguna que la igualdad entre las partes se vea vulnerada por un procedimiento legalmente tramitado. A raíz de ello, en casos complejos, como entre un ciudadano y el Presidente de la República, es la misma ley quien le da competencia para conocer el caso a los Tribunales Superiores, protegiendo el principio de igualdad y al ciudadano, asegurando así la debida imparcialidad.

\section{B.- Las facultades de árbitro arbitrador que posee la Comisión Arbitral en cuanto al procedimiento}

Otro punto importante referente al procedimiento administrativo de resolución de conflictos descrito en la Ley de Concesiones, consiste en que la Comisión Arbitral posea facultades de árbitro arbitrador en cuanto al procedimiento. Ante esto el artículo $36^{\circ}$ bis inciso $8^{\circ}$ del decreto analizado, establece que:

9 Damaska, Mirjan, Las caras de la justicia y el poder del Estado. Análisis comparado del proceso legal, Editorial Jurídica de Chile, Santiago, 2000, p. 46.

10 Sentencia I. Corte de Apelaciones de Santiago, Causa Rol 3950-2009. 
"La comisión, en cuanto designe sus integrantes y se constituya, deberá determinar el modo en que se le formularán las reclamaciones y el mecanismo de notificación que empleará para poner en conocimiento de las partes las resoluciones o decisiones que emita, y dictará las demás normas de procedimiento que estime pertinentes. Entre estas últimas se encontrarán las que regulen la audiencia de las partes y aquellas correspondientes a los mecanismos para recibir las pruebas y antecedentes que las partes aporten" [el subrayado es mío].

Como deja de manifiesto el artículo transcrito, nuevamente se está vulnerando el debido proceso, pues al entregar la determinación de las reglas del procedimiento a la voluntad de la Comisión Arbitral y, a su vez, negar la posibilidad de recurrir ante otra autoridad para reclamar de una resolución derivada de la consecución de este proceso -tal como señalé anteriormente-, se estaría dando pie a eventuales arbitrariedades por parte de los sentenciadores al no respetarse dentro de este las garantías de las partes.

En base a esto y a fin de resguardar los intereses y derechos de los particulares, la Constitución Política de la República en su artículo 19 № 3 inciso $5^{\circ}$ establece:

"Corresponderá al legislador establecer siempre las garantías de un procedimiento y una investigación racionales y justos".

Este precepto, otorga un mandato al legislador y dice relación con la creación de procedimientos que aseguren garantías mínimas a las partes, como lo son un emplazamiento válido, recurrir ante otra autoridad para reclamar de una resolución; independencia; imparcialidad, eficiencia y no arbitrariedad del sentenciador, el cual ejerce jurisdicción y quien debe estar legal y previamente instaurado, elementos que se revisaron al analizar el debido proceso.

En este sentido, si se entrega a la Comisión Arbitral la facultad de establecer libremente el procedimiento a seguir en caso de someter un asunto a su conocimiento, el legislador desatiende aquel mandato constitucional, pues este órgano no está Ilamado a respetar la racionalidad y la justicia del proceso. Agrava esta situación el hecho que los particulares no cuenten con un recurso procesal que controle la actuación de esta institución. Cabe hacer presente que ni aun esta facultad está entregada a los árbitros arbitradores, pues estos están obligados a guardar en sus procedimientos las reglas que las partes hayan expresado en el acto constituido. 
Por otro lado, la situación descrita vulnera el principio de legalidad ${ }^{11}$, mediante el cual todo ejercicio del Poder Público debe encontrarse sometido a la voluntad de la ley, en la medida en que este procedimiento escapa de cualquier clase de control que puedan ejercer ya sea la Administración Pública o el Poder Judicial.

Recordemos que, además, este procedimiento no contempla recurso procesal alguno en sede judicial, y el control preventivo que realiza o puede realizar la Contraloría General de la República recae sobre la licitación misma y el contrato de concesión, mas no en la tutela de las garantías procesales.

Sin perjuicio que en el contrato de concesión puede estar contemplado un procedimiento, de todas formas la Comisión está facultada para modificarlo, pues así lo establece el artículo 36 bis, que señala lo siguiente: "la comisión, en cuanto designe sus integrantes y se constituya, deberá determinar el modo en que se le formularán las reclamaciones y el mecanismo de notificación que empleará para poner en conocimiento de las partes las resoluciones o decisiones que emita, y dictará las demás normas de procedimiento que estime pertinentes".

De lo anterior se puede concluir, entonces, que en la determinación del procedimiento no existe límite alguno para la Comisión Arbitral, contrariando el debido proceso en la medida que: 1) existirán tantos procedimientos como comisiones se formen, y 2) las partes no sabrán a qué atenerse en cuanto a cuál será el procedimiento, ya que solo podrán conocerlo cuando la Comisión Arbitral se constituya.

Por su parte, esta situación transgrede de igual forma el principio de seguridad o certeza jurídica ${ }^{12}$ de los particulares, pues si bien el artículo $36^{\circ}$ bis inciso $8^{\circ}$ le entrega la atribución a la Comisión Arbitral de establecer el procedimiento al que someterán las partes ante una controversia suscitada durante la concesión, no se establece

11 Por principio de legalidad debe entenderse la vinculación de los diferentes poderes del Estado a la ley; a esa ley que ha sido elaborada por la representación popular asentada en el Parlamento. Solo en su referencia a dicha norma encuentran, pues, tales poderes la condición -entendida aquí, en su doble acepción, a la vez como "fundamento" (vinculación positiva) y como "condicionamiento"- de su capacidad de actuar (Vinculación negativa) (Kamel Kazor, Aleste, Principio De Legalidad Y Criterios De Vinculación Positiva Y Negativa En La Constitución /en/ Revista de Derecho, [on line], vol. VIII, diciembre 1997, [Fecha Consulta: 27 de Noviembre de 2010], pp. 91-96, "Disponible en la World Wide Web: http://mingaonline.uach.cl/scielo.php?pid=S0718-09501997000200005\&script=sci_arttext\#r3").

La vinculación negativa se impone como límite a la actividad de la administración, en el sentido de no contradecir la Constitución. Es esta dimensión la que infringe la disposición en comento.

12 La seguridad jurídica es un valor estrechamente ligado a los Estado de Derecho que se concreta en exigencias objetivas de: corrección estructural (formulación adecuada de las normas del ordenamiento jurídico) y corrección funcional (cumplimiento del Derecho por sus destinatarios y especialmente por los órganos encargados de su aplicación). (Enrique Pérez Luño, La seguridad Jurídica como...). En este sentido, la norma infringiría el primero, en la medida en que no existe una formulación del procedimiento, sino que solo un reenvío a la Comisión. 
la forma en que este procedimiento será notificado a los interesados o cómo deberá ser determinado - la ley señala que solo se adoptarán las normas que "estime pertinentes"-, provocando inseguridad e indefensión, lo que se traduce en un perjuicio para las partes en la medida en que ellas quedarán en la incertidumbre de si el procedimiento será ventajoso o no para la consecución de sus intereses, y por tanto no poder determinar si elegir o no algún acuerdo o suscribir un contrato de transacción.

La vulneración de estos importantes principios es absolutamente perjudicial para un Estado de Derecho, ya que estos cumplen un rol fundamental en las democracias liberales contemporáneas, contribuyendo, de cierto modo, a consolidar la legitimidad del derecho mismo, en cuanto lo hace más racional ${ }^{13}$.

Para reforzar lo expuesto, cabe destacar que la Ley de Concesiones le otorga a la Comisión Arbitral las facultades de árbitro arbitrador en cuanto al procedimiento. No obstante, el Código Orgánico de Tribunales se refiere a los árbitros arbitradores en su artículo 223 inciso $3^{\circ}$ de la siguiente manera:

"El arbitrador (...) no estará obligado a guardar en sus procedimientos (...) otras reglas que las que las partes hayan expresado en el acto constitutivo del compromiso, y si éstas nada hubieren expresado, a las que se establecen para este caso en el Código de Procedimiento Civil"14.

En virtud de lo transcrito, claramente la Ley de Concesiones incurre en una contradicción, ya que por un lado le otorga la facultad a la Comisión de determinar el modo en que se le formularán las reclamaciones, el mecanismo de notificación que empleará y determinar las normas de procedimiento que estime conveniente, y por otro, señala que este órgano tendrá las facultades de un árbitro arbitrador, asimilándolo de esta forma a uno de ellos.

Al respecto, es del caso señalar que si el árbitro arbitrador está obligado a ceñirse a reglas de procedimiento convenidas por las partes o, en subsidio, por las reglas del procedimiento establecidas en el párrafo $2^{\circ}$ del Título VIII del Libro III del Código de Procedimiento Civil, es justamente para proteger los principios anteriormente señalados: debido proceso, legalidad y seguridad jurídica.

13 "Disponible en la World Wide Web: http://www.scielo.cl/scielo.php?pid=S0718-34372007000100017\&script=sci_ arttext".

14 Artículo 636 del Código de Procedimiento Civil.

214 Revista Chilena de Derecho y Ciencia Política - ISSN Impreso: 0718-9389 / ISSN on line: 0719-2150 


\section{C.- La suspensión de los efectos del acto administrativo reclamado por parte del concesionario.}

Para poder analizar este nuevo punto conflictivo, es de suma importancia previamente centrarnos en la naturaleza jurídica de la Comisión Arbitral.

\section{C.1. Naturaleza jurídica de la Comisión Arbitral}

Para abordar este asunto, me referiré al concepto que el Diccionario de la Real Academia de la Lengua Española le otorga a la palabra "Comisión", definiéndola como: "Conjunto de personas encargadas por la ley, o por una corporación o autoridad, de ejercer unas determinadas competencias permanentes o entender en algún asunto específico"115. Frente a esta acepción, no existe duda que nos encontramos realmente frente a una comisión cuyo asunto específico es la de conocer las controversias emanadas con motivo del contrato de concesión.

Sin embargo, la ley, al denominar este órgano como "Comisión Arbitral" y no simplemente "Comisión", obedece a que la intención del legislador era la de asimilar los integrantes de esta institución a un juez arbitral, en este caso a un árbitro mixto.

No obstante, y en virtud de lo expuesto, esto no es efectivo, ya que si bien la Comisión Arbitral comparte muchas de las características de un juez árbitro, no obedece a una de las características primordiales que los rigen, cual es, la de someter su actuar a las reglas que fijen las partes o bien al procedimiento establecido por ley ${ }^{16}$.

\section{C.2. La Comisión Arbitral es un organismo especial}

En conclusión, se trata de una comisión especial a la cual se aplican de forma subsidiaria las reglas de los árbitros arbitradores, pero que tiene regulaciones propias, y como tal, es un órgano autónomo que se encarga de dirimir cuestiones relativas al contrato de concesión, cuyas funciones son primero como intérprete, conociendo acerca de las controversias o reclamaciones que se produzcan con motivo de la interpretación o aplicación del contrato de concesión o a que dé lugar su ejecución y también las que versen acerca del monto de la indemnización ${ }^{17}$; y segundo, como Ministro de Fe, para efectos de certificar que el concesionario abandone la obra o

\footnotetext{
15 Definición de la RAE, "Disponible en la World Wide Web: http://buscon.rae.es/drael/SrvltConsulta?TIPO_ BUS=3\&LEMA= comisi\%F3n".

16 Código de Procedimiento Civil, Libro III.

17 Art. 28 ter, inc. $7^{\circ}$ del Decreto $N^{\circ} 900$.
} 
interrumpa injustificadamente el servicio ${ }^{18}$ y para la declaración de incumplimiento grave del contrato de concesión ${ }^{19}$.

Como se puede deducir, estas funciones se enmarcan siempre dentro del contrato de concesión, y es así como este órgano nace por y para asistir a una correcta ejecución del contrato, no pudiendo exceder ni tener otras atribuciones que las señaladas precedentemente.

\section{C.3. Suspensión de los efectos del acto administrativo}

Ahora bien, este tribunal jurisdiccional de características especiales, tiene la facultad de suspender los efectos del acto administrativo reclamado a petición del concesionario, lo cual podría asimilarse procesalmente a una orden de no innovar, sin perjuicio, de las diferencias substanciales que existen entre ellas.

La orden de no innovar (ONI) es una medida cuya finalidad es conservar la situación de hecho o de derecho que se encuentra en curso al momento de interponer una acción determinada de carácter jurídico, en relación a personas y/o bienes comprendidos en el proceso.

Tomando en consideración esta definición de carácter general podemos diferenciar la orden de no innovar establecida en la legislación procesal civil y la instaurada en la legislación procesal administrativa.

La primera puede definirse como la consecuencia esperada a la concesión del recurso en el solo efecto devolutivo, establecida en el artículo 192 del Código de Procedimiento Civil, y en virtud de la cual el apelante puede obtener de parte del tribunal de alzada la orden de suspender el curso del procedimiento en primera instancia, es decir, si se decreta la orden de no innovar se suspenden los efectos de la resolución recurrida y se paraliza su cumplimiento.

En la segunda acepción puede conceptualizarse como la facultad que nuestro ordenamiento jurídico entrega a los tribunales superiores de justicia en los procesos en que se ventila la legalidad de un acto administrativo, que se traduce en una resolución judicial trascendental que paraliza momentáneamente los efectos de un acto administrativo, es decir, su ejecutividad ${ }^{20}$.

8 Art. 37 del Decreto No 900.

9 Art. 28 del Decreto $N^{\circ} 900$.

20 Oelckers Camus, Osvaldo, La suspensión de los efectos del acto administrativo debido a la orden de no innovar /en/ Revista de Derecho de la Universidad de Valparaíso, № XVI, 1995, Valparaíso, Chile. 
En consecuencia, las características o elementos comunes que emanan de la orden de no innovar, sea en materia procesal civil o procesal administrativa, son:

1.- La suspensión o paralización de los efectos de un acto.

2.- Sus alcances recaen en una resolución judicial o en un acto administrativo.

3.- Es una facultad que radica exclusivamente en los tribunales superiores de justicia.

A su vez, si comparamos los elementos generales de la orden de no innovar recién establecidos, con la facultad que la ley de concesiones le otorga a la Comisión Arbitral -la suspensión de los efectos del acto administrativo reclamado- podemos encontrar las siguientes similitudes y diferencias:

Respecto al primer punto, no encontramos discrepancias, puesto que, para ambas instituciones procesales el objetivo primordial es, precisamente, suspender o paralizar los efectos de un acto o resolución.

El segundo aspecto es más controvertido, pues los alcances de la orden de no innovar recaen de forma exclusiva en una resolución o en un acto administrativo. Si bien es cierto, la atribución de suspender los efectos de la que ha sido investida la Comisión Arbitral, también recae en un acto administrativo, estos no son los mismos. Para comprenderlo mejor, realizaremos la distinción.

El acto administrativo en que recae la orden de no innovar es aquel que se encuentra definido en el artículo $3^{\circ}$ de la Ley 19.880, como la decisión formal que emite un órgano de la Administración del Estado en el cual se contienen declaraciones de voluntad realizadas en el ejercicio de una potestad pública, los cuales tomarán la forma de un decreto supremo o de una resolución.

En cambio, el acto administrativo sobre el que recae la facultad de suspensión de la Comisión es "el contrato de concesión". En este sentido, el legislador ha cometido un error conceptual, puesto que si bien el contrato de concesión es de orden administrativo, este no puede ser calificado como un acto administrativo, pues ambos tienen orígenes jurídicos distintos. El primero nace al Derecho como una declaración unilateral de voluntad ${ }^{21}$, y el segundo, como un acuerdo de voluntades entre las partes, Estado y ciudadano.

21 En este sentido, Poblete, Julia, Actos y Contratos Administrativos, LexisNexis, Santiago de Chile, Tercera Edición, 2007, p. 10. 
No obstante, el artículo $36^{\circ}$ ter del Decreto MOP № 900 podría interpretarse en el sentido que el acto administrativo susceptible de suspensión por la Comisión Arbitral es el decreto de adjudicación que da a lugar la licitación. Sin embargo, esto no sería procedente bajo ningún punto de vista; primero, porque este decreto supremo emanado del Ministerio de Obras Públicas solo tiene por finalidad el perfeccionamiento del contrato de concesión mediante su publicación en el Diario Oficial; y segundo, porque la Comisión Arbitral solo tiene competencia para conocer de las reclamaciones o controversias que se produzcan con motivo de la interpretación o aplicación del contrato.

Finalmente, el tercer elemento en comparación, y uno de los más importantes, radica su diferencia en que la facultad que emana de la orden de no innovar recae de manera exclusiva y excluyente en los Tribunales Superiores de Justicia, esto es, Corte de Apelaciones y Corte Suprema.

Para ratificar esta idea encontramos en el ámbito administrativo, tanto en materia municipal como regional, el denominado "Reclamo de Ilegalidad". El primero, por un acto municipal, establecido en el Artículo 122, letra e) de la Ley18.696 Orgánica Constitucional de Municipalidades; y el segundo, por actos u omisiones del Gobierno Regional contemplado legalmente, en el Artículo 102 de la Ley 19.175 "Orgánica Constitucional sobre Gobierno y Administración Regional", como en el Auto Acordado de la Excelentísima Corte Suprema sobre tramitación del Recurso de Protección de fecha 24 de junio de 1992. La competencia para conocer de dichos reclamos se encuentra radicada en las Ilustrísimas Cortes de Apelaciones y en la Excelentísima Corte Suprema, las cuales tendrán la facultad para suspender temporalmente los efectos de un acto administrativo ${ }^{22}$.

Por su parte, en el ámbito procesal civil y tal como su definición lo señala, la orden de no innovar se concede con la interposición de un recurso en el solo efecto devolutivo; en este sentido, el Ilamado a conocer será el tribunal de alzada, o en términos amplios el tribunal Ad Quem, es decir, un tribunal superior.

En cambio, la atribución de suspender los efectos emanados del contrato de concesión recae -como se ha dejado en evidencia anteriormente- en un órgano autónomo, con características y atribuciones propias, y de única instancia.

Una vez establecidas las diferencias existentes entre estas instituciones análogas, podemos determinar que el otorgamiento de esta facultad a la Comisión Arbitral atenta contra los derechos y garantías de las partes del conflicto sometido a su conocimiento, en base a los siguientes argumentos:

22 Oelckers Camus, Osvaldo, obr. cit., p. 1. 
I.- El hecho que un órgano con las características de la Comisión Arbitral tenga la facultad de suspender los efectos que derivan netamente del contrato de concesión, está vulnerando el derecho contractual que tienen las partes. No debemos olvidar que a la luz de lo establecido en el artículo 1545 del Código Civil ${ }^{23}$, debe afirmarse que al igual que un contrato entre privados, el contrato administrativo, celebrado o perfeccionado previo procedimiento de formación de la voluntad contractual, es una ley para los contratantes, no siendo posible en forma unilateral, ni aun, por ejemplo, bajo pretexto de la Administración de ejercer su potestad administrativa invalidatoria ${ }^{24}$.

A su vez, este contrato se rige por las normas legales y reglamentarias que lo tipifican o regulan, por las normas y cláusulas de las bases de licitación, por la oferta adjudicada y por las demás concernientes prescripciones técnicas, generales y particulares. Frente al perfeccionamiento del contrato, ambas partes -Administración Pública y contratante particular- asumen la obligación de ejecutar de buena fe dicho contrato y cumplir las obligaciones que se imponen para cada una de ellas. Es más, existen posiciones doctrinarias ${ }^{25}$ que afirman que frente al incumplimiento de la $\mathrm{Ad}$ ministración, no le cabe al contratante particular incumplir las suyas propias, sino solamente pedir la resolución del contrato, pero únicamente en caso que ello se encuentre previsto o sancionado en él ${ }^{26}$.

En vista de lo anterior, si una comisión especial tiene la atribución y potestad para suspender -cuando ella unilateralmente estime que existen motivos graves y calificados- los efectos y obligaciones que las partes haciendo uso de sus facultades han convenido, se está vulnerando una ley de carácter especialísimo, creada por los contratantes con la finalidad única de regular los asuntos que se suscitan entre ellos.

Es más, ni aun los tribunales ordinarios de justicia cuentan con tal prerrogativa, pues como se ha mencionado precedentemente, el efecto originado de la orden de no innovar recae específicamente en declaraciones unilaterales de voluntad emanadas de un órgano de la Administración del Estado mediante el ejercicio de una potestad pública -acto administrativo- o en una resolución o sentencia definitiva que emana precisamente de un órgano jurisdiccional de menor rango o jerarquía ${ }^{27}$, pero

23 Artículo 1545: Todo contrato legalmente celebrado es una ley para los contratantes, y no puede ser invalidado sino por su consentimiento mutuo o por causas legales.

24 Corte de Apelaciones de Santiago, Causa Rol № 186-2000, de 24/04/2001.

25 En este sentido, Meyer, David, Fath Meyer, Jean M., Evaluación de las contrataciones públicas en Chile, Reforma del Estado [on line], vol. II, "Disponible en la World Wide Web: http://www.cepchile.cl/dms/ lang_1/doc_3530.html", p. 579.

26 Moraga Klenner, Claudio, Contratación Administrativa, Editorial Jurídica de Chile, Santiago de Chile, primera edición, 2010, p. 202.

27 Esto responde precisamente a la figura de Estado Jerárquico predominante en Chile. 
jamás en un acto jurídico bilateral del que se originan derechos y obligaciones para las partes.

Para reafirmar esto último, cabe mencionar que un contrato celebrado en conformidad a la ley -sea administrativo, sea civil-genera un lazo jurídico entre los contratantes de goza de tanta fuerza que, para solicitar su rescisión o resolución ante un organismo jurisdiccional competente, las partes deben necesariamente someterse a un procedimiento de lato conocimiento, es decir, a un procedimiento ordinario.

En consecuencia, y a modo de resumen, la circunstancia por medio de la cual la Comisión Arbitral, a través de un procedimiento de carácter breve en comparación a uno ordinario -establecido y dispuesto en el Libro II del Código de Procedimiento Civil- pueda suspender los efectos de un acto convenido por las partes, vulnera la tutela judicial efectiva que el Estado, mediante sus órganos judiciales, debe promover.

Es así como Bello y Jiménez plantean que el Estado debe garantizar el conjunto mínimo de garantías procesales sin lo cual el proceso judicial no será justo, razonable y confiable, garantías éstas que permiten la efectividad de la justicia, que aseguran el derecho material de los ciudadanos frente a los órganos de Administración de Justicia y que le establece limitaciones al poder ejercido por el Estado por medio de los tribunales para afectar a los ciudadanos ${ }^{28}$.

\section{Conclusiones}

En base a lo expuesto en el desarrollo de este texto, me permito formular cuatro principios relacionados con el debido proceso, que deben estar presentes en la Ley de Concesiones Públicas, con el objeto de salvaguardar la tutela efectiva de los particulares en el procedimiento que consagra dicha norma.

\section{Que el procedimiento contenga las reglas de la doble instancia}

La circunstancia que las partes carezcan de cualquier forma de control sobre la resolución emanada por parte de la Comisión Arbitral, quedando de esta manera en la indefensión frente a las eventuales arbitrariedades que se pudieren cometer -sea de forma o de fondo-, puede ser remediado o subsanado -en parte- mediante la interposición de un Recurso de Queja ${ }^{29}$.

28 Bello, Humberto, Jiménez, Dorgy, Tutela Judicial Efectiva y otras Garantías Constitucionales Procesales, Ediciones Paredes, Caracas, Venezuela, Primera Edición, 2004.

29 Causa Rol 3950 - 2009. Para remediar este problema, se puede empezar por seguir el criterio que esta-

220 Revista Chilena de Derecho y Ciencia Política - ISSN Impreso: 0718-9389 / ISSN on line: 0719-2150 
EL PROCEDIMIENTO DE RESOLUCIÓN DE CONTROVERSIAS EN EL DECRETO MOP № 900...

Este recurso de carácter especial encuentra su asidero jurídico en el Código Orgánico de Tribunales, específicamente en su artículo 545, que dispone:

"El recurso de queja tiene por exclusiva finalidad corregir las faltas o abusos graves cometidos en la dictación de resoluciones de carácter jurisdiccional. Sólo procederá cuando la falta o abuso se cometa en sentencia interlocutoria que ponga fin al juicio o haga imposible su continuación o definitiva, y que no sean susceptibles de recurso alguno, ordinario o extraordinario, sin perjuicio de la atribución de la Corte Suprema para actuar de oficio en ejercicio de sus facultades disciplinarias". El precepto señala además que "El fallo que acoge el recurso de queja contendrá las consideraciones precisas que demuestren la falta o abuso, así como los errores u omisiones manifiestos y graves que los constituyan y que existan en la resolución que motiva el recurso, y determinará las medidas conducentes a remediar tal falta o abuso. En ningún caso podrá modificar, enmendar o invalidar resoluciones judiciales respecto de las cuales la ley contempla recursos jurisdiccionales ordinarios o extraordinarios, salvo que se trate de un recurso de queja interpuesto contra sentencia definitiva de primera o única instancia dictada por árbitros arbitradores". Por último, concluye expresando que "En caso que un tribunal superior de justicia, haciendo uso de sus facultades disciplinarias, invalide una resolución jurisdiccional, deberá aplicar la o las medidas disciplinarias que estime pertinentes. En tal caso, la corte dispondrá que se dé cuenta al tribunal pleno de los antecedentes para los efectos de aplicar las medidas disciplinarias que procedan, atendida la naturaleza de las faltas o abusos, la que no podrá ser inferior a amonestación privada" [El subrayado es mío].

Por su parte, el órgano jurisdiccional llamado a conocer de este recurso es la Ilustrísima Corte de Apelaciones, conforme a lo establecido en el artículo $63 \mathrm{~N}^{\circ} 2$ letra b) del cuerpo legal recién mencionado. Esta disposición señala que:

"Las Cortes de Apelaciones conocerán: $2^{\circ}$. En única instancia: b) de los recursos de queja que se deduzcan en contra de los jueces de letras, jueces de policía local, jueces árbitros y órganos que ejerzan jurisdicción dentro de su territorio jurisdiccional".

Como se advierte de los preceptos legales transcritos, dicho tribunal está expresamente facultado para modificar, enmendar o invalidar la resolución objeto de un recurso de queja expedida por un árbitro arbitrador; sin perjuicio de ello, este órgano también

blece la Corte de Apelaciones de Santiago en causa Rol 3950 - 2009, en el sentido de declarar admisible, y por tanto, revisar la sentencia dictada por la Comisión Arbitral, a través del Recurso de Queja que pueda deducir alguna de las partes. De esta forma, se asegura la posibilidad de revisión del obrar de esta Comisión, limitando o derechamente negando la posibilidad de que se pueda alejar del debido proceso. 
goza de competencia, con las mismas atribuciones, para conocer de un recurso de queja interpuesto en contra de la resolución emanada por una Comisión Arbitral. Sin embargo, el presupuesto que sustenta esta prerrogativa es distinto en ambos casos.

En la primera situación, el artículo 545 del ya mencionado texto legal expresamente lo declara, al establecer que "se trate de un recurso de queja interpuesto contra sentencia definitiva de primera o única instancia dictada por árbitros arbitradores".

Ahora bien, como se ha dejado de manifiesto a lo largo de este trabajo, la Comisión Arbitral, a pesar de tener facultades de un árbitro arbitrador, estas solo serán aplicables en cuanto al procedimiento, pues con la última modificación efectuada a la Ley de Concesiones en enero de este año, su resolución deberá ser fundada con arreglo a derecho, siendo entonces, un árbitro mixto. Por lo cual, esta parte del precepto no le sería aplicable.

No obstante, la disposición recién mencionada señala también que la Corte de Apelaciones "en ningún caso podrá modificar, enmendar o invalidar resoluciones judiciales respecto de las cuales la ley contempla recursos jurisdiccionales ordinarios o extraordinarios". A contrario sensu, la parte transcrita de la norma dispone una excepción a la prohibición estipulada por el legislador para ejercer las atribuciones que ahí se señalan, cual es, que la resolución no sea susceptible de recurso jurisdiccional, sea este ordinario o extraordinario. En consecuencia, siendo la sentencia emanada de una Comisión Arbitral no susceptible de recurso alguno, quedaría facultada la Corte - por vía de la Queja- de modificarla, enmendarla o invalidarla, lo que no resulta ser -en todo caso- el objetivo buscado por el legislador.

Por su parte, algo de la doctrina ha sostenido que este recurso es de carácter exclusivamente disciplinario ${ }^{30}$, aduciendo para ello como principal fundamento un antecedente sistemático. Destacan el hecho que el legislador ubicó este recurso en el Titulo XVI del Código Orgánico de Tribunales, el que se ocupa "de la jurisdicción disciplinaria y de la inspección y vigilancia de los servicios judiciales". Sin embargo, si bien este autor está de acuerdo con dicha clasificación, no es menos cierto que la finalidad que busca el legislador mediante la creación de este recurso es, además, la corrección de "las faltas o abusos de gravedad" que se pudieren cometer en la dictación de resoluciones ${ }^{31}$, quedando esta idea plasmada de forma expresa en la norma que lo define y establece.

30 Tavolari Oliveros, Raúl, Recurso de Casación y Queja, Editorial Jurídica ConoSur, Santiago de Chile, 1996, p. 10. y Piedrabuena Richard, Guillermo, El recurso de Queja y la Queja después de las modificaciones de la ley $N^{\circ} 19.374$ /en/ Fallos del Mes, Documento Nº6, 1995, p. 13.

31 Así queda reflejado en el mensaje enviado con fecha 20 de octubre de 1992, por el entonces Presidente de la República don Patricio Aylwin y su Ministro de Justicia don Francisco Cumplido, al Senado, con la finalidad de modificar el Recurso de Queja. 
En vista de lo anterior, solo puede deducirse entonces que el Recurso de Queja tiene por objeto principal remediar, a través, de medidas conducentes, las faltas o abusos cometidos y además, en este caso particular, modificar, enmendar o invalidar las resoluciones judiciales que emanan de la Comisión Arbitral, sin perjuicio de la medida disciplinaria que sería aplicable al caso concreto.

\section{Que la notificación sea de acuerdo a la ley, otorgando a la contraria un tiempo de emplazamiento razonable para preparar una defensa adecuada}

Esta delegación que hace la ley a la Comisión Arbitral acerca de la adopción de su propio procedimiento impide a las partes poder conocer de antemano cuáles serán las condiciones a las que se someterán una vez iniciado el proceso, lo cual deja a ambas en la indefensión de conocer las reglas mínimas de carácter funcional.

Esto repercute, en primer lugar, en una notificación legal y debido emplazamiento. Cabe recordar que no solo se requiere que la notificación sea válida, es decir, que sea realizada de acuerdo a los requisitos legales, sino que además que exista un tiempo que sea suficiente para que la parte demandada pueda preparar adecuadamente su defensa. En este caso, el procedimiento no contempla ningún método de notificación ni tampoco establece un transcurso de tiempo que permita a la parte preparar en forma adecuada su defensa, entregándole a la Comisión Arbitral la facultad de establecer las formas que "estime pertinentes" para adoptar un procedimiento, lo que de ninguna manera deja a salvo el derecho a defensa de las partes. De esta forma, se ven impedidas de señalar lo que sea relevante para sus intereses.

III. Que exista real e igual oportunidad, entre las partes, de producción y refutación de prueba, y dictación de la sentencia con respeto a la Constitución y a las leyes

La tutela al debido proceso se traduce en que la sentencia emanada de un ente jurisdiccional respete el Ordenamiento Jurídico, tanto respecto de los requisitos formales como de los requisitos de fondo. En este sentido, la sentencia de la Comisión Arbitral debería respetar los contenidos formales que se exigen para cada sentencia y además respetar los requisitos de fondo necesarios para que el fallo contenga una debida argumentación de la decisión del asunto.

Otro aspecto aún más importante es el que se refiere a la prueba ilícita. Este procedimiento no la menciona ni la prohíbe en los términos en que lo hacen los nuevos procedimientos de familia y laboral, en los cuales se señala que la prueba ilícita 
carecerá de valor ${ }^{32}$. Este elemento hace referencia a que las partes no podrán hacer valer aquellas pruebas que hayan violentado los derechos fundamentales de las personas o que su obtención fue hecha de manera ilícita, lo que implica una dimensión de resguardo del debido proceso superior respecto de las garantías de las partes que el anticuado procedimiento ordinario civil, que no se refiere a la prueba ilícita bajo ningún aspecto.

Se hace necesario que el legislador reconozca la posibilidad de que las partes actúen lícitamente y que por tanto debe existir un límite a las pruebas que pueden presentar al tribunal para acreditar sus dichos, así como estableció que la Comisión Arbitral apreciará la prueba conforme a la sana crítica, a lo que se refiere el punto siguiente.

La Comisión Arbitral está obligada a apreciar la prueba conforme a las reglas de la sana crítica, por lo que se encuentra obligada, al menos, a respetar las máximas de la experiencia, las reglas de la lógica y los principios científicamente afianzados. En la sentencia, además, la Comisión debe hacerse cargo de toda la prueba rendida, señalando cuáles hechos da por probados y a través de qué medios, justificando por qué ha preferido un medio probatorio por sobre otro.

En este sentido, si la Comisión llega a excederse de sus atribuciones y no respeta estas reglas elementales, con la legislación actual, las partes no estarían provistas de herramientas que permitan la modificación de esta resolución, a menos, claro está, que se recurran a una interpretación en el sentido de que el Recurso de Queja sí debe ser admisible, como se postula en este trabajo.

\section{Derecho a defensa y a un procedimiento racional y justo}

Por todo lo dicho y lo expuesto latamente, referente a este punto, resulta evidente que no existen las garantías suficientes para que las partes puedan preparar su defensa, o bien, puedan reclamar contra el agravio que se les ha provocado con la dictación de la sentencia.

32 Artículo 31 de Ley 19.968 que crea los Tribunales de Familia: Artículo 31.- Exclusión de prueba. El juez de familia, luego de estudiar la admisibilidad de las pruebas ofrecidas, de resolver las convenciones probatorias y de escuchar a las partes que hubieren comparecido a la audiencia preparatoria, ordenará fundadamente que se excluyan de ser rendidas en el juicio aquellas que fueren manifiestamente impertinentes, tuvieren por objeto acreditar hechos públicos y notorios, resulten sobreabundantes o hayan sido obtenidas con infracción de garantías fundamentales. Las demás serán admitidas y se ordenará su rendición en la audiencia de juicio respectiva.

Artículo $434 \mathrm{~N}^{\circ} 4$ inciso tercero del Código Laboral: Con todo, carecerán de valor probatorio y, en consecuencia, no podrán ser apreciadas por el tribunal las pruebas que las partes aporten y que se hubieren obtenido directa o indirectamente por medios ilícitos o a través de actos que impliquen violación de derechos fundamentales (El subrayado es mío). 
En este sentido, las partes no pueden prever el procedimiento que las regirá, no tienen conocimientos acerca de la forma en que las resoluciones les serán notificadas ni el tiempo que tendrán para oponerse a ellas. Los medios de prueba se encuentran limitados a los establecidos en el Código de Procedimiento Civil y no incorporan los modernos medios de prueba (pero el tribunal al apreciarlos tiene limitaciones que son conocidas) y al pronunciar su fallo, las partes no pueden solicitar su revocación o anulación.

\section{Bibliografía}

Actas Oficiales de la Comisión Constituyente, Santiago de Chile, 1989.

Alvarado Velloso, Adolfo, El Debido Proceso de la Garantía Constitucional, Editorial Zeus, Buenos Aires, Argentina, 2003.

Barros Bourie, Enrique, Tratado de Responsabilidad Extracontractual, Editorial Jurídica de Chile, Santiago de Chile, 2006.

Coordinación de Concesiones de Obras Públicas, Marco Legal, [on line], [Fecha Consulta: 22 de Noviembre de 2010], "Disponible en la World Wide Web: http:// www.concesiones.cl/acercadelacoordinacion/funcionamientodelsistema/Paginas/MarcoLegal.aspx".

Corte de Apelaciones de Santiago, Canales Valenzuela María con Ruta 5 Tramo Talca Chillán S.A., 2330, Marzo 28, 2005.

Corte de Apelaciones de Santiago, MOP contra Comisión Arbitral, 3950 - 2009, 2009.

Carnelutti, Francesco, La Prueba Civil, Editorial Depalma, Buenos Aires, Argentina, 1982.

Corte Suprema de Justicia, Del Recurso de Casación /en/ Repertorio de Legislación y Jurisprudencia Chilenas, IV, 11, 1999.

Couture, Eduardo, Fundamentos del Derecho Procesal Civil, Editorial Roque Depalma, Buenos Aires, Argentina, 1958.

Evans, Enrique, Los Derechos Constitucionales, Editorial Jurídica de Chile, Santiago, 2004.

FigueroA, Juan Eduardo, El arbitraje en los contratos de concesión de obras públicas en Chile /en/ Cámara de Comercio de Santiago, [on line], [Fecha Consulta: 22 de Noviembre de 2010], "Disponible en la World Wide Web: http://www. camsantiago.com/articulos_online_3.htm". 
Alejandro Preuss Lazo

Fisco de Chile - Ministerio de Obras Públicas - Dirección de Obras Públicas con Comisión Arbitral del Contrato de Concesión de Obra Pública Fiscal, 3950 - 2009 (Corte de Apelaciones de Santiago, Julio 03, 2009).

Jurisprudencia al Día, Derecho Público, Tomo I, Editorial LexisNexis, Santiago de Chile, 2007.

Lepe, Paula, El Sistema de Concesiones de Obras Públicas /en/ Gaceta Jurídica, No 323, 2007.

MÉNDEZ, Enrrique, Distribución del Riesgo: Clave del éxito de programa de concesiones en Chile. Concesiones y Suelo Urbano: Dos Claves para la Inversión, 2004.

Mosquera, Mario, Seguridad Jurídica y Derecho Procesal /en/ Seguridad Jurídica, Universidad de Chile, Santiago de Chile, 1986.

Pantoja, Rolando, Derecho Administrativo: 120 años de Cátedra, Editorial Jurídica de Chile, Santiago de Chile, 2008.

Pérez, Gisell, Reseña de Libro "Principios generales del Derecho Público" de Moderne, Franck /en/ Revista Chilena de Derecho, Pontificia Universidad Católica de Chile, 2007, pp. 192-195.

Revista Actualidad Jurídica, Universidad del Desarrollo, Santiago de Chile, 2002.

Román, Cristian, Responsabilidad Patrimonial de la Administración del Estado y de su concesionario vial frente al usuario lesionado /en/ Revista de Derecho de la Universidad de Valparaíso, 2006, pp. 233 y ss.

Sánchez, Camilo, Sistema de Concesiones de Chile y su Desarrollo Futuro, Ministerio de Obras Públicas, Santiago de Chile, 2008.

Tavoları Oliveros, Raúl, Recursos de Casación y Queja. Nuevo Régimen. Editorial ConoSur, Santiago de Chile, 1996.

YusefF Quirós, Gonzalo, Fundamentos de la Responsabilidad Civil y Responsabilidad Objetiva, Editorial La Ley, Santiago de Chile, 2000.

226 Revista Chilena de Derecho y Ciencia Política - ISSN Impreso: 0718-9389 / ISSN on line: 0719-2150 